\title{
Estrategias en torno a las formas de apropiación y organización del espacio en un "barrio de migrantes" de la ciudad de Córdoba, Argentina*
}

\author{
María José Magliano** \\ María Victoria Perissinotti*** \\ Denise Zenklusen****
}

El propósito de este trabajo es indagar sobre las estrategias de apropiación y organización del espacio que despliegan las familias peruanas en un "barrio de migrantes" de la ciudad de Córdoba, Argentina. Este barrio, ubicado en la periferia este de la ciudad y conocido como Los Artesanos, se comenzó a consolidar como tal desde el año 2009, a partir del asentamiento de un número importante de familias migrantes que actuaron como residentes pioneros, especialmente de origen peruano, aunque también habitan allí familias bolivianas, paraguayas y argentinas. En este análisis se busca reflexionar acerca de las distintas estrategias de supervivencia que ponen en práctica las familias migrantes en contextos de exclusión y desigualdad social. Para desarrollarlo se ha optado por una metodología cualitativa que ha privilegiado la observación participante y las entrevistas en profundidad a mujeres y varones peruanos que residian en el barrio en el momento de practicarse la investigación.

Palabras clave: migración peruana, marginalidad urbana, estrategias de supervivencia, espacio público-privado, Córdoba.

Fecha de recepción: 12 de abril de 2013.

Fecha de aceptación: 17 de junio de 2013.

* Este trabajo se desprende del proyecto de investigación "Los nudos ciegos de la desigualdad. Género, etnia y clase en la migración latinoamericana en Córdoba”, subsidiado y acreditado por la Secretaría de Ciencia y Técnica de la Universidad Nacional de Córdoba (SECyT-UNC), Argentina.

** Centro de Investigaciones y Estudios sobre Cultura y Sociedad, Consejo Nacional de Investigaciones Científicas y Técnicas-Universidad Nacional de Córdoba (CIECS, Conicet-UNC). Dirección postal: Rondeau 467, 1er piso, CP 5000, Córdoba, Argentina. Correo electrónico: <majomagliano@gmail.com>.

*** Centro de Investigaciones y Estudios sobre Cultura y Sociedad, Consejo Nacional de Investigaciones Científicas y Técnicas-Universidad Nacional de Córdoba (CIECS, Conicet-UNC). Dirección postal: Rondeau 467, ler piso, CP 5000, Córdoba, Argentina. Correo electrónico: <vperissinotti@gmail.com>.

**** Centro de Investigaciones y Estudios sobre Cultura y Sociedad, Consejo Nacional de Investigaciones Científicas y Técnicas-Universidad Nacional de Córdoba (CIECS, Conicet-UNC). Dirección postal: Rondeau 467, ler piso, CP 5000, Córdoba, Argentina. Correo electrónico: <denisezenklusen@gmail.com>. 
Strategies on the Forms of Appropriating and Organizing Space in a Migrant Neighborhood in the City of Córdoba, Argentina

This work seeks to explore the strategies for appropriating and organizing the space established by Peruvian families in a "migrant neighborhood" in the city of Córdoba, Argentina. This neighborhood on the outskirts of the city, known as Los Artesanos, began to be consolidated in 2009, following the settlement of a large number of migrant families who became pioneering residents. They were mainly Peruvians, though they also included Bolivian, Paraguayan and Argentinian families. This analysis reflects on the various survival strategies implemented by migrant families in contexts of social exclusion and inequality. To this end, it has implemented a qualitative methodology involving participant observation and in-depth interviews of Peruvian men and women living in the neighborhood at the time of the study.

Key words: Peruvian migration, urban marginality, survival strategies, public-private space, Córdoba.

\section{Introducción}

La intención de este trabajo es indagar acerca de las estrategias de apropiación y organización del espacio que despliegan las familias peruanas en un "barrio de migrantes" de la ciudad de Córdoba, Argentina. ${ }^{1}$ Este barrio, ubicado en la periferia este de la ciudad y conocido como Los Artesanos, se comenzó a consolidar como tal desde el año 2009 a partir del asentamiento de un número importante de familias migrantes que actuaron como residentes pioneros, especialmente de origen peruano, aunque también habitan allí familias bolivianas, paraguayas y argentinas.

Asimismo, nos preguntamos qué hay de particular en la articulación entre la migración reciente hacia la ciudad de Córdoba, principalmente focalizada en la migración peruana, y las estrategias de apropiación y organización del espacio en un barrio de dicha ciudad. Específicamente pretendemos dilucidar algunas de las estrategias que despliegan los y las migrantes en pos de la consolidación y la estabilidad de su proyecto migratorio. Para ello nos detendremos en dos cuestiones que nos parecen centrales en la reconstrucción de sus experiencias migratorias: por un lado, el acceso a la casa propia y las implicaciones y sentidos que

${ }^{1}$ La categoría "barrio de migrantes" responde al modo en que los habitantes del barrio nombran a su espacio de residencia. 
los y las migrantes le otorgan en el marco del proyecto migratorio; por el otro, las dinámicas laborales de los migrantes peruanos, varones y mujeres, y el modo en que se articulan con las formas de organización del espacio privado-doméstico en un marco territorial específico. ${ }^{2}$

En las sociedades contemporáneas las ciudades se convierten en espacios privilegiados para entender las estrategias de supervivencia que ponen en práctica las familias migrantes (Sassen, 2007: 136). La noción de "estrategia" que recorre estas páginas se asienta en la premisa de que los individuos y las familias poseen un margen de acción y de decisión, por más restringido que éste sea (Zamorano Villarreal, 2003: 165).

En términos teórico-metodológicos, este artículo forma parte de aquellos trabajos preocupados por reflexionar críticamente acerca de los procesos de producción y reproducción de las desigualdades sociales en los espacios urbanos, entendidos como una construcción histórica y política (Wacquant, 2007a: 21), y de las estrategias que los actores llevan adelante para hacer frente a escenarios de exclusión social en contextos de marginalidad urbana. De modo específico, el texto se concentra en la problemática actual de acceso a la vivienda por parte de los y las migrantes que llegan a la ciudad de Córdoba en Argentina desde los países sudamericanos, y en la conformación de barrios urbano-marginales en dicha ciudad, entendiendo que los mismos no son más que "una retraducción espacial de las diferencias económicas y sociales" (Wacquant, 2007a: 21). Asimismo, recupera la perspectiva de género para reflexionar sobre los modos de organización del espacio doméstico-privado en el contexto del barrio Los Artesanos en virtud de las inserciones laborales de los migrantes peruanos, varones y mujeres. ${ }^{4}$

2 Siguiendo la argumentación de Segato (2006: 130), el territorio es espacio representado y apropiado, una de las formas de aprehensión discursiva del espacio. De modo específico, tiene que ver con su administración y, por lo tanto, con su delimitación, clasificación, habitación, uso, distribución y, muy especialmente, identificación.

${ }^{3}$ La cuestión de la marginalidad urbana es de gran interés para las ciencias sociales. En este trabajo pensamos en la marginalidad urbana como la expresión de lógicas de exclusión y desigualdades sociales en las sociedades contemporáneas. Existe una abundante producción bibliográfica sobre el modo en que las ciudades se organizan, administran sus espacios y reproducen lógicas de dominación y desigualdad. En este sentido podemos mencionar los trabajos de Auyero (1999), Marcuse (1993), Merklen (1991), Sassen (2007), Wacquant (2007a y 2007b).

${ }^{4}$ Existe una vasta literatura que aborda la vinculación entre el mercado de trabajo y la dimensión de género para entender los recorridos laborales de varones y mujeres. Entre otros podemos mencionar las investigaciones de Arriagada, 2006; Carrasco, 2003; Carrasco y Mayordomo, 1999; Cerruti, 2003; De la O y Guadarrama, 2006; García y de Oliveira, 2007. Asimismo, desde los estudios de género se ha planteado que la dicotomía 
La migración peruana hacia Argentina en general y Córdoba en particular está relacionada con la búsqueda de mejores oportunidades socioeconómicas. En líneas generales, se trata de un flujo que se incrementó en los años noventa, con un gran componente femenino yjoven, con una alta concentración en las zonas urbanas, en especial en el Área Metropolitana de Buenos Aires (Cerruti, 2005; Rosas, 2010). Córdoba no ha escapado a esta tendencia. Según muestran Falcón Aybar y Bologna (2013: 237), la migración peruana hacia la ciudad comenzó a crecer, en correspondencia con el flujo hacia Argentina, durante la década de los noventa y como resultado de los procesos económicos y políticos por los que transitó Perú. De acuerdo con los datos que ofrece el censo de población provincial del año 2008, el 90\% de los migrantes peruanos que llegan a la provincia de Córdoba permanecen en la ciudad capital, y el fenómeno es fundamentalmente urbano. La elección de dicha ciudad como lugar de llegada se vincula principalmente con la búsqueda de oportunidades laborales en un marco de redes de contacto e información. En este sentido, un amplio porcentaje de los y las migrantes peruanos que llegaron a Córdoba en los últimos 20 años tenía conocidos que vivían en la ciudad (parientes y/o amigos), que los orientaron en la elección del destino y les facilitaron la llegada a la ciudad ayudándolos en la obtención de trabajo y alojamiento en viviendas colectivas (Falcón Aybar y Bologna, 2013: 252). ${ }^{5}$

En relación con la metodología, hemos privilegiado las técnicas de recolección y análisis cualitativo, en especial la observación participante y las entrevistas en profundidad a mujeres y varones migrantes de origen peruano que viven en el barrio. La reconstrucción de las trayectorias migratorias y de las estrategias que despliegan los y las migrantes se conformó en un marco de proximidad y confianza, producto de los propios recorridos de un trabajo de campo cualitativo. Es precisamente a partir de esa proximidad y confianza que pudimos compartir esos

público-privado es una construcción social, cultural y económica que responde a proyectos políticos e ideológicos particulares. En este trabajo recuperamos la categoría privado-doméstico para designar el espacio del hogar, asociado fuertemente a la figura femenina. Para profundizar sobre este tema véase: Carrasquer et al., 1998; Jelin, 2010; Maquiera, 2001; Murillo, 2006; Torns, 2008.

${ }^{5}$ La temática de la migración peruana hacia Argentina ha cobrado mayor interés en la última década. Muchos de los trabajos dedicados a esta cuestión se ocuparon del Área Metropolitana de Buenos Aires, principal destino de la población migrante peruana en Argentina (Cerruti, 2005; Rosas, 2007, 2008, 2010). Con relación a Córdoba, existen pocos trabajos que abordan este proceso migratorio, entre ellos podemos mencionar a Falcón Aybar y Bologna, 2013 y León Prado, 2010. 
"espacios", verlos, pensarlos y confrontarlos con nuestras propias categorías y visiones del mundo. Cada una de las entrevistas y conversaciones informales con los y las migrantes tuvo lugar en el barrio, principalmente en sus casas. En el transcurso del trabajo de campo hemos compartido momentos de trabajo y de ocio, participado en eventos y celebraciones familiares y barriales, ingresado en sus "universos privados", y hemos tenido acceso a distintas dimensiones de su cotidianeidad. Desde el comienzo del trabajo de campo (julio de 2012), hemos reunido un total de 10 entrevistas con encuentros periódicos y 16 registros etnográficos. ${ }^{6}$ La mayor parte de los habitantes del barrio son parejas jóvenes (entre 20 y 40 años) que llegaron hace poco tiempo a la ciudad de Córdoba provenientes de diferentes regiones de Perú.

En la primera parte de este artículo nos ocuparemos de reconstruir las "llegadas" de los y las migrantes peruanos al barrio Los Artesanos de la ciudad de Córdoba con el propósito de indagar sobre la dimensión espacial de las desigualdades sociales. En la segunda parte nos concentraremos en analizar el modo en que el espacio privado-doméstico es delimitado y reorganizado por los migrantes peruanos, varones y mujeres, en relación con sus trayectorias laborales, marcadas por la precariedad y la informalidad, en un marco territorial concreto. Este texto asume el desafío de visibilizar una problemática relevante presente en Argentina y otros países de América Latina vinculada con las dificultades que enfrentan los sectores populares -dentro de los cuales se concentran los colectivos migrantes de los países de la región sudamericana- para acceder a la vivienda. Pero además busca mostrar el modo en que los y las migrantes, aun en contextos de exclusión y desigualdad, despliegan distintas estrategias en pos de asegurar su subsistencia y la de sus familias, disputando determinadas construcciones de género relacionadas con la dicotomía público-privado y con la definición de trabajos femeninos y masculinos.

\section{Sobre las llegadas al barrio: la "casa propia" como factor de consolidación del proyecto migratorio}

Llegamos a Córdoba en el 2009, desde Lima. Al principio vivíamos en una pieza que alquilamos a la señora que nos trajo [...] pero no pudimos seguir pagando el alquiler y una mujer conocida de Pedro [su esposo] nos con-

${ }^{6}$ Los nombres de los entrevistados, mujeres y varones, han sido modificados para preservar su anonimato. 
tó de unos terrenos que se estaban tomando. Vinimos a verlos, pero a mí no me gustaron, estaba todo lleno de yuyos, ${ }^{7}$ llegaban hasta por arriba del auto [y señala el auto viejo y en desuso que está estacionado en su patio, al frente nuestro]. Así que le dije "vente tú solito, yo no voy". Pero finalmente acepté venir y comenzamos a construir la casa [la casa en donde habitan es muy precaria, de madera] [...] Nos vinimos porque había muchos compatriotas y porque había espacio. Cuando nos vinimos nos dijeron que tomemos hasta allá (y señala hacia el sur, hacia la casa de una de sus vecinas), pero era mucho. Cuando llegamos había muy pocas casas construidas, pero ahora ya casi no hay más espacio [Estela, migrante peruana, 26 de septiembre de 2012, Córdoba].

Estela y Pedro conforman una pareja joven de migrantes peruanos para quienes el desplazamiento hacia Argentina (vía Chile) fue su primera experiencia migratoria. Tienen un hijo, Mario, de casi tres años, y también vive con ellos Ricardo, el hermano de Estela, quien llegó desde Lima en noviembre de 2011. Junto con otras familias peruanas, son los primeros pobladores del barrio Los Artesanos y su casa está ubicada sobre lo que sería la calle principal del lugar. El testimonio de Estela respecto a su llegada se repite en las narraciones de muchos de los habitantes del barrio. La imposibilidad de afrontar el pago del alquiler, en varios casos de viviendas colectivas, los llevó a la búsqueda de nuevos horizontes habitacionales.

A lo largo de nuestro trabajo de campo, el acceso a la vivienda apareció en los relatos de las personas entrevistadas como una de las temáticas más recurrentes y a la que mayor importancia se le asigna. Mientras que quienes han logrado hacerse de una casa propia se refieren a este acontecimiento como un punto de quiebre en su experiencia migratoria, los que aún no lo han logrado lo marcan permanentemente como uno de sus mayores anhelos. Sin embargo, dadas las condiciones socioeconómicas que enfrenta un amplio conjunto de los y las migrantes recientes que llegan desde los países sudamericanos, y dadas sus principales trayectorias laborales en Córdoba, caracterizadas por su precariedad e informalidad, el acceso a la vivienda por medio del mercado inmobiliario formal resulta una posibilidad remota. Por el contrario, requiere un trabajo de apropiación del espacio que permita la construcción de un territorio que les resulte habitable.

7 "Yuyos" es una palabra que se utiliza en Argentina para designar a las hierbas no cultivadas que crecen en los terrenos, en especial en aquellos que se encuentran en desuso o deshabitados. 
A la luz del trabajo etnográfico realizado, nos interesa problematizar ese proceso a partir de indagar las diversas estrategias que ponen en juego los migrantes, varones y mujeres, en pos de acceder a la casa propia, hecho que resulta clave en la consolidación de sus proyectos migratorios. Veremos así cómo la construcción del barrio Los Artesanos, en tanto espacio apropiado, trazado, recorrido y delimitado (Segato, 2006: 130), se erige como una estrategia que estas personas despliegan para sortear algunos de los tantos obstáculos que las condiciones estructurales de una sociedad excluyente y desigual les imponen.

Lejos de ser una excepción, la construcción de dicho barrio presenta características similares a las de otros barrios de la ciudad de Córdoba en los que se asientan migrantes recientes de origen sudamericano. Asociado a las trayectorias laborales fuertemente marcadas por la precarización y la vulnerabilidad, se produce un desplazamiento de los y las migrantes de origen peruano a zonas específicas de la ciudad, en especial periféricas (Falcón Aybar y Bologna, 2013). Así, mientras que en las últimas décadas del siglo Xx los y las migrantes peruanos se asentaban en barrios tradicionales del centro de la ciudad, como Alberdi, en la actualidad la imposibilidad de acceder a viviendas en esos lugares los desplaza hacia las zonas urbano-marginales. ${ }^{8}$

La obtención, o la imposibilidad de obtener una vivienda en espacios urbanos se relaciona fuertemente con factores como la discriminación, la falta de recursos y el funcionamiento del mercado inmobiliario que limitan las opciones con que la población migrante cuenta, y no sólo ella, lo cual da origen al fenómeno de la "segmentación residencial". Específicamente en relación con los migrantes, Terrones Ribas (2005: 204) señala que, dada su pertenencia de clase, sólo pueden aspirar a cierto segmento del mercado de la vivienda que corresponde a las "zonas degradadas", a las cuales se accede por medio del mercado informal.

En las "llegadas" a Córdoba de los y las migrantes de origen peruano, las redes sociales han jugado un rol central. La migración se sustenta en diversas redes de relaciones que les permiten a los sujetos elegir su lugar de destino, llegar y establecerse en él. ${ }^{9}$ La mayoría de

8 Alberdi es un barrio tradicional de la ciudad de Córdoba ubicado en la zona central de la misma que reúne a un importante número de migrantes peruanos. Si bien se registra una creciente dispersión de la población peruana en la ciudad, Alberdi es, en términos simbólicos, el "lugar" de la comunidad peruana en Córdoba.

${ }^{9}$ En el campo de los estudios migratorios, la cuestión de las redes sociales y su impacto en las dinámicas migratorias internacionales ha ocupado un lugar relevante desde las últimas décadas. Algunos de los trabajos que han abordado esta temática son: Grasmuck y Pessar, 1999; Gregorio, 1998; Lomnitz, 1994; Pedone, 2006; Suárez Navas, 2004. 
nuestros entrevistados, varones y mujeres, remarcaron la importancia que implica para ellos haber contado con algún conocido que los recibiera al llegar. Estas redes están conformadas por familiares, amigos o personas recomendadas por algún conocido. Generalmente se trata de personas de la misma nacionalidad que llevan algún tiempo viviendo en el lugar de destino y cuya situación es comparativamente más estable en términos socioeconómicos. Analía, una joven peruana que vive en Los Artesanos, resumía la importancia de las redes sociales para su llegada a Córdoba:

E: ¿Por qué elegiste Córdoba?, ¿por qué no otro lugar de Argentina, como Buenos Aires?

A: Porque mi amiga se venía para acá, y tenía pieza y trabajo. En Buenos Aires no tengo a nadie. No tenía dónde llegar y lo más triste es no tener a dónde llegar [Analía, migrante peruana, 21 de noviembre de 2012]. ${ }^{10}$

Así, las redes facilitan la llegada a la ciudad al ayudar al migrante a encontrar un lugar donde vivir en el momento del arribo, a incorporarse al mercado laboral y, posteriormente, a detectar ciertos espacios en donde pueden comenzar a construir una vivienda que, aunque precaria, puedan considerar como propia. En este contexto, las redes posibilitan que los migrantes recientes se instalen, en un primer momento, en pensiones o piezas alquiladas. En muchas oportunidades, estas piezas pertenecen a las mismas personas que "los traen", y en general son casas rentadas por peruanos, quienes subalquilan piezas a sus "compatriotas". Estos espacios son concebidos por los migrantes como un lugar transitorio no sólo debido al costo del alquiler, sino también porque las piezas son compartidas y no se suele permitir la presencia de niños. Pero fundamentalmente se les considera un lugar de paso porque no es la casa propia.

Sin embargo dado que estas personas no pueden acceder a la casa propia por medio del mercado inmobiliario formal, aparecen entonces otros espacios ubicados en la periferia de la ciudad, que en su mayoría

10 Analía tiene 27 años y llegó a Córdoba desde Lima en el año 2010 con una amiga. Al comienzo de su estadía compartió una pieza con su amiga en una casa del barrio Alberdi en el centro de la ciudad, subalquilada por migrantes peruanos que habían migrado previamente. Al poco tiempo de haber llegado consiguió trabajo en casa de una familia como empleada doméstica, una de las principales ocupaciones de las mujeres peruanas en Córdoba, bajo la modalidad "cama adentro". Esta situación se modificó cuando quedó embarazada. En ese momento llegó al barrio Los Artesanos para instalarse en la casa de una "compatriota". A partir de ahí su inserción laboral se reorientó al trabajo de costura, actividad que aprendió en Córdoba. 
son terrenos fiscales que hasta el momento de su ocupación constituían terrenos baldíos, los cuales se presentan como una alternativa frente a la urgencia de conseguir un lugar dónde vivir. También las redes migratorias les facilitan el acceso a estos espacios. En general, la noticia de que se están ocupando terrenos circula de modo informal entre los vecinos de las pensiones y las casas en las que viven los familiares y los amigos. Para el caso de Los Artesanos, específicamente, se fue configurando una red social étnica (Gregorio, 1998: 179) entre migrantes peruanos que permitió su llegada a estos terrenos baldíos. Muchas de las familias peruanas que se instalaron en el lugar no se conocían previamente. Luego de la llegada de estos "pioneros", poco a poco comenzó a poblarse el área con viviendas precarias que ellos mismos fueron construyendo, en principio de madera y, con el paso del tiempo, de material.

La noción de necesidad emerge en numerosas entrevistas para explicar la decisión de asentarse en estos espacios. En este sentido es que planteamos la importancia de pensar la construcción de Los Artesanos en relación con los procesos de desigualdad y exclusión a los que se han visto sometidos los migrantes que en los últimos años han llegado a la ciudad de Córdoba desde los países de la región sudamericana. La concepción de segmentación residencial a la que hace referencia Terrones Ribas (2005) resulta fundamental para comprender la configuración de los procesos a través de los cuales los migrantes logran acceder sólo a un sector específico de la ciudad y a un tipo particular de viviendas. Puesto que no se trata de un proceso aislado, sino que presenta continuidades con otros barrios urbano-marginales de la ciudad de Córdoba, rescatar la historia de la construcción de Los Artesanos permite indagar en esta dirección.

Los Artesanos puede ser definido en términos de Merklen (1991) como un asentamiento. Se encuentra ubicado en la periferia este de la ciudad de Córdoba y está constituido por terrenos fiscales del Estado nacional, propiedad del Ferrocarril. El lugar se comenzó a habitar a mediados de 2009 mayoritariamente por un grupo de personas provenientes de Perú que en ese momento se encontraban buscando otro lugar donde vivir, ya que no podían continuar costeando el alquiler; aunque también viven allí familias argentinas, bolivianas y paraguayas. En la actualidad residen en Los Artesanos más de 280 familias. Según nos comentaron algunos de nuestros entrevistados, un grupo de argentinos delimitó algunos terrenos y afirmó que era propietario de los mismos. Posteriormente comenzaron a venderlos a precios que, 
comparados con los del mercado formal, resultaban accesibles. Sin embargo, por tratarse de terrenos fiscales, la venta se mantuvo en el plano informal y la propiedad se garantizó por la permanencia y no por una escritura que avalara la posesión. De este modo, en términos legales la ocupación de terrenos corresponde a una "usurpación", práctica que se encuentra penada por la ley. En este sentido, algunos vecinos reconocen que fue "ilegal" la manera en que accedieron a los terrenos, pero aclaran que lo hicieron por necesidad. Así reconstruía Pedro, esposo de Estela, su experiencia de llegada a Los Artesanos:

Cuando nosotros vinimos a Córdoba, primero vivimos en una pieza que nos costaba como 500 pesos, después nos fuimos a una más chica donde vivíamos con otro hombre. Y después nos vinimos para acá [...] Nosotros en el 2010 vinimos y había una persona que estaba vendiendo terrenos. El hombre que nos lo vendió era un argentino que había venido antes y se había agarrado varios terrenos y después los vendía. Nosotros compramos porque en realidad no te queda otra que comprar. Cuando necesitas, no te queda otra [Pedro, migrante peruano, 12 de diciembre de 2012, Córdoba].

La alusión "no te queda otra" surge como una manera de justificar la "ocupación” del terreno. En otras palabras, "la situación de pobreza en que viven los ocupantes [de los asentamientos] refuerza la legitimidad de la ocupación" (Merklen, 1991: 30). Con respecto a este punto cabe advertir que dicha práctica no es un fenómeno aislado, sino que constituye una de las estrategias históricas a través de las cuales muchas familias de sectores populares acceden a espacios en donde habitar. Tal como señala Guber (2004: 13), "la ocupación de tierras es un fenómeno extendido en América Latina. Esas tierras suelen ser áreas deprimidas del medio urbano por su hacinamiento, falta de servicios públicos, inundabilidad y exposición a derrumbes”. Los Artesanos, al igual que muchos otros barrios en donde se ubican los sectores populares -y entre ellos los migrantes recientes- de la ciudad de Córdoba, presenta estas características. Sumado a la precariedad de las viviendas, Los Artesanos cuenta con escasos servicios básicos (alumbrado, agua corriente, recolección de la basura y gas) y sus calles de tierra suelen inundarse cuando llueve. ${ }^{11}$

11 En los recorridos del trabajo de campo hemos observado cómo las condiciones climáticas adversas influyen fuertemente en la vida cotidiana del barrio. Dado que el terreno en donde se asienta carece de infraestructura -como sistemas de drenaje y desagües-, las grandes tormentas provocan daños y roturas en las viviendas. 
Ahora bien, pese a que la estrategia de ocupación es común a una buena parte de la población de los sectores populares, los asentamientos construidos por migrantes en la ciudad de Córdoba presentan características particulares que resulta importante analizar. A nuestro entender, éstas se relacionan estrechamente con el hecho de que los migrantes no conciben estos espacios como transitorios sino que constituyen el lugar definitivo de su residencia. Esto se vincula con aquello que planteábamos previamente acerca de la importancia que adquiere en el marco del proyecto migratorio dejar de pagar un alquiler a partir del acceso a la casa propia. Así pues, es el proyecto migratorio como tal el que se juega en el proceso de obtención de una vivienda a través de la "ocupación" de un territorio. De otro modo, dicho proyecto comienza a ser cuestionado en tanto los esfuerzos que realizaron desde su salida de Perú -la distancia de sus afectos, las largas jornadas laborales, etc.- no tendrían sentido si ello no estuviera acompañado por mejoras o expectativas de mejoras en la vida cotidiana en el lugar de destino. En la mayoría de los relatos de nuestros entrevistados el ideal de la casa propia aparece asociado con la noción de logro. Como nos explicaba Pedro, "para vivir en una pensión, me hubiese quedado en Perú" (Pedro, 12 de diciembre de 2012, Córdoba).

A diferencia de las "villas", ${ }^{12}$ en donde las personas se asientan según van llegando sin una planificación previa, en Los Artesanos la delimitación de las manzanas, la demarcación de las calles y el loteo de los terrenos se realizó con anterioridad a la llegada de los vecinos. ${ }^{13}$ En los relatos de los migrantes, varones y mujeres, surge reiteradamente la idea del esfuerzo que realizaron para construir un espacio similar a un "barrio", no a una "villa": "queremos que esto se parezca más a un barrio y no a una "villa", expresó un migrante peruano frente a los efectos de las tormentas de verano (Óscar, migrante peruano, 11 de diciembre de 2012, Córdoba). ${ }^{14}$

${ }^{12}$ El término "villa" deviene de "villa miseria", noción que es utilizada en Argentina para designar a aquellos lugares estigmatizados y situados en lo más bajo del sistema jerárquico de los sitios que componen una metrópoli (Wacquant, 2007a: 13).

${ }_{13}$ Tal como plantea Merklen (1991), esta organización social previa es propia de los asentamientos, lo que los diferencia de las villas. Estas últimas producen tramas urbanas muy irregulares, están organizadas a partir de intrincados pasillos donde por lo general no pueden pasar vehículos, y sus habitantes las perciben como lugares transitorios; los asentamientos, por el contrario, se distinguen principalmente por sus trazados urbanos regulares y planificados, a la vez que quienes viven en ellos los constituyen como espacios de residencia a mediano y largo plazos.

${ }^{14}$ Óscar llegó de Lima a mediados de la década pasada y es también uno de los primeros habitantes de Los Artesanos. Allí vive con su esposa, Mariana, y su pequeña hija. Se dedica al trabajo en la construcción. 
En la disposición espacial de las viviendas se advierte un esfuerzo constante para delimitar cada casa y diferenciarla de la calle. Así, prácticamente ninguna casa se encuentra sin cercar y, de igual manera, casi todas tienen algo que funciona como una puerta de entrada. Esto resulta posible en función de una gran variedad de recursos que despliegan tanto para construir tapias ${ }^{15}$ como para colocar ciertos portones de acceso. Los elásticos de los colchones funcionan a modo de puerta de entrada; tablas de machimbre ${ }^{16}$ se fraccionan y disponen alrededor del terreno para lograr cercos; alambres atados funcionan a modo de cerrojos. Como mencionábamos, las estrategias que despliegan los y las migrantes ponen de manifiesto el margen de acción y de decisión con que cuentan a fin de construir un espacio habitable que responda a los parámetros de un barrio, y puede comprenderse al concebir que para ellos este espacio constituye el lugar definitivo de su residencia, y asimismo al entender que el acceso a la casa propia es un factor que puede condicionar el proyecto migratorio y la permanencia en el país de destino. Los testimonios de Marta y Adriana ilustran estas premisas:

\section{E: ¿Te gusta Córdoba?}

M: Sí, me gusta, pero también extraño Perú. Tengo ganas de volver.

E: ¿Volver definitivamente?

M: No, volver de visita. Desde que me vine esta última vez que no voy, hace ya siete años, en el 2005. Tengo a mi mamá allá, pero es muy caro ir. Además ya acá tengo mi vida, tengo mi casa, allá no tengo nada [Marta, migrante peruana, 29 de agosto de 2012, Córdoba]. ${ }^{17}$

\section{E: ¿Cómo está compuesta su familia, Adriana?}

A: Yo vivo aquí con mi marido, mis hijos y mis nietos están en Perú, nos vinimos buscando trabajo hace ya siete años.

E: ¿Y piensa quedarse acá?

A: Por ahora sí, pero yo quiero volver, mi marido ya está acostumbrado, además acá tenemos nuestra casa, que la hicimos nosotros con mucho de límite.

${ }^{15}$ Las tapias son paredes que se construyen con tierra amasada y que suelen servir

16 Sistema de ensamblado de tablas de madera.

17 Marta tiene 36 años y llegó por primera vez a Córdoba en el año 2002 para trabajar como empleada doméstica "cama adentro", dejando en Lima a su marido y a su hija. Luego de un año de permanecer en Córdoba retornó a su Perú natal para volver nuevamente en el año 2005, esta vez con toda su familia. Junto con la familia de Estela y Pedro, la suya es una de las "pioneras" del barrio, una referente importante de Los Artesanos. 
esfuerzo, pero también uno tiene que jalar donde está la familia [Adriana, migrante peruana, 4 de diciembre de 2012, Córdoba]. ${ }^{18}$

Si bien las realidades de las familias de Marta y Adriana son diferentes, producto fundamentalmente del modo de migrar -migración de toda la familia en su conjunto y migración de algunos de sus miembros-, el acceso a la casa propia incide en la permanencia en Córdoba. Los esfuerzos que implican la migración y la distancia con parte de sus familias comienzan a dar sus frutos o se justifican cuando se logran ciertos objetivos en el lugar de destino. La obtención de una vivienda es uno de ellos, quizás el más importante. Pero éste no es un proceso inmediato, las características específicas de estos lugares hace que en un comienzo los y las migrantes los perciban como "inhabitables", como recordaba Estela sobre su primera impresión de Los Artesanos.

Así, luego de "ocupar" el terreno las familias comienzan a "hacerlo habitable": sacan las hierbas, mueven las piedras y empiezan a construir sus casas. En un principio, ante a la urgencia por ocuparlo pero frente a la dificultad económica de afrontar la construcción de una vivienda de material, suelen levantar casas de madera, que emergen como una solución provisoria hacia la definitiva. La construcción de viviendas de materiales más sólidos y duraderos se torna entonces la aspiración principal para las familias migrantes que residen en el barrio. Con el paso del tiempo, las familias emprenden el proceso de construcción de las mismas, a las que dedican no sólo gran cantidad de tiempo, sino también de recursos económicos. Durante este proceso comienzan a sentir el espacio habitado como un lugar propio, no necesariamente con relación a una posesión garantizada formalmente, sino gracias al trabajo social que han desplegado en los terrenos. La demarcación de las calles, el loteo y la red de relaciones que se van estableciendo en torno al espacio del barrio contribuyen a decantar el imaginario de un espacio propio:

Nosotros construimos todo esto, conseguimos la luz y el agua. Tengo fotos de cuando conseguimos el agua. Nosotros limpiamos el terreno, antes había unas piedras así de grandes [nos muestra unas piedras grandes que

18 Adriana llegó desde Trujillo en el año 2005 con su marido; dejó a sus hijos e hijas en Perú, así como a sus dos nietas. Ha viajado algunas veces a ver a su familia (en el año 2012 se fue a Perú por dos meses a visitar a sus hijos, hijas y nietas). En Córdoba se dedica al trabajo doméstico en la casa de una familia y a la vez posee un pequeño comercio en su casa; su marido, Roberto, se desempeña en la construcción. 
aún permanecen en el patio de su casa] para poder construir las casas [Marta, 13 de noviembre de 2012, Córdoba]. ${ }^{19}$

En la constitución y la consolidación del espacio como "barrio" las mujeres ocupan un papel importante, pues incluso participan en ocasiones en las tareas de la construcción junto con los varones. Generalmente en los días no laborables se acercan al barrio los familiares y vecinos para ayudar en la edificación. Además, son las mujeres migrantes, con Marta a la cabeza, quienes han gestionado el acceso a algunos de los servicios básicos con que cuenta el barrio, como el agua, la luz y la recolección de la basura (aunque esporádica); asimismo han desempeñando un rol clave en las situaciones adversas por las que ha transitado el barrio. Son ellas quienes realizan los trámites; quienes mantienen vínculos con las dependencias del Estado, en especial aquellas vinculadas con el área social, y con las organizaciones no gubernamentales que se acercan al barrio; son ellas quienes se encargan, a través de diferentes estrategias, de reunir los fondos necesarios; quienes recolectan las firmas y llevan a cabo otras tareas importantes. ${ }^{20}$ A través de estas acciones, un espacio que era ajeno y distante fue configurándose e identificándose como propio.

Para los habitantes de Los Artesanos, la construcción de una vivienda, aunque sea de materiales precarios, funciona como una manera de garantizarse la propiedad. Pero no sólo ello: quienes viven en estos espacios no pueden abandonar su terreno, en tanto se trata de una ocupación "ilegal” en la que la propiedad no está garantizada por una escritura (Merklen, 1991). En este contexto, no sólo es necesaria la construcción de una vivienda, sino también, y especialmente, "estar" y "permanecer" en el barrio. La "presencia" resulta una estrategia clave para asegurar la propiedad y evitar que ésta sea "ocupada”. En pos de "estar" el mayor tiempo posible en la casa, ponen en práctica una serie de arreglos familiares y laborales, como veremos más adelan-

${ }^{19}$ Cuando se asentaron las primeras familias, en el año 2009, el barrio no contaba con ningún servicio básico (luz eléctrica, gas, agua, recolección de residuos). Como resultado de las iniciativas y acciones de los propios vecinos, en especial de las mujeres de origen peruano, en la actualidad el barrio cuenta con luz eléctrica, una boca de agua corriente por vivienda y la recolección de basura una vez por semana.

${ }^{20}$ Existe una vasta literatura sobre el rol de la mujer de los sectores populares en la acción colectiva barrial. Los Artesanos no escapa a esta tendencia y han sido las mujeres, mayoritariamente migrantes de origen peruano, quienes han encabezado las diferentes acciones en pos de "mejorar" y hacer "habitable" el barrio. Para profundizar sobre esta cuestión, véase: Barrancos, 2008; Bolos, 2008; Carrasco, 2003; Jelin, 2010; Lagarde, 2003; Vaggione y Avalle, 2007. 
te, atravesados por una percepción de inseguridad que influye directamente en las formas de organización familiar en el contexto de residencia. Así lo relataba Estela:

Lo que pasa que acá tienes que ocupar el terreno porque si no te lo ocupa otro [...] Si estás en tu casa no te roban, no se te meten [Estela, 17 de octubre de 2012, Córdoba].

Una familia peruana del barrio salía de su casa para trabajar y unas personas aprovecharon y usurparon la casa. Nosotros nos organizamos y los botamos [...] es que los peruanos estamos mucho fuera de casa porque estamos trabajando [Estela, 26 de septiembre de 2012, Córdoba].

Esta situación se resuelve, en términos generales, de dos maneras: por un lado, la precaución de que las viviendas se hallen siempre habitadas por alguien de la familia (en ocasiones son los propios niños quienes asumen esta tarea mientras sus padres trabajan fuera del barrio); por el otro, el lugar de trabajo se traslada a la casa. En ambos casos es el trabajo el que estructura el proyecto migratorio y las estrategias que ponen en práctica los migrantes, atravesando sus trayectorias, experiencias, decisiones y formas de organización familiar. En un contexto reducido de posibilidades de inserción productiva, la opción de que el espacio privado-doméstico se convierta en el ámbito productivo es cada vez más buscada, primordialmente para quienes se dedican a labores de costura. El trabajo en casa, además de proporcionar tranquilidad a muchas familias migrantes en tanto asegura la "presencia" en la vivienda, es especialmente valorado en términos de los beneficios que puede llegar a ocasionar el "cuentapropismo".

\section{Sobre los recorridos laborales de las familias migrantes y las redefiniciones en torno al espacio privado-doméstico en Los Artesanos}

Llegamos al barrio cerca de las 15:30 horas. Igual que el miércoles pasado, casi no se veía gente por las calles. Mientras esperamos que llegara la persona que íbamos a entrevistar, Pedro, un vecino del barrio, salió de su casa, nos saludó y nos invitó a pasar. "Estela está en la cocina”, nos dijo. “¿Saben dónde es la cocina?”, nos preguntó. Nos dijo que estaba trabajando, que no la molestábamos, que pasáramos. Pasamos y Pedro sale con un vecino. 
Cuando llegamos a la puerta de la cocina saludamos a Estela y pedimos permiso para entrar; nos dijo que pasemos. La cocina-taller (porque allí tiene las máquinas de coser) es una pieza construida enteramente en madera, con el piso de tierra y con el techo de nylon y de madera. Como máximo tiene tres por cinco metros, espacio en el que se amontonan tres mesas de trabajo (con tres máquinas de coser, una en cada mesa), un televisor, una mesa y dos heladeras. Estela estaba sentada en la mesa de la esquina, la que se ubica exactamente al frente del televisor que estaba prendido aunque se veía muy mal, sobre una pila de telas negras que estaba cosiendo. Nos acercamos, la saludamos con un beso y nos quedamos conversando con ella. Sobre la mesa donde trabaja Pedro, estaba la parte de arriba de la prenda. Según nos explicó Estela, "él cose esa parte y le pone las etiquetas mientras yo coso la parte de abajo”. “¿Dónde aprendiste a coser?", le preguntamos. "Aprendí a coser en Perú, antes de venir para acá, me enseñó Pedro”. A los pocos minutos llega Pedro y se dispuso también a coser [Registro de campo, 3 de octubre de 2012, Córdoba].

La inserción productiva de Estela y Pedro se repite en muchas familias peruanas que viven en Los Artesanos así como también la disposición de las viviendas, en especial las cocinas, que fungen como espacios de trabajo productivo. La casa de Raquel y Jaime, ubicada sobre la calle principal del barrio, se organiza de manera similar a la de Pedro y Estela. En el espacio destinado a la cocina están ubicadas dos máquinas de coser en las que ambos trabajan. Además poseen en su casa un pequeño kiosco para abastecer a la gente del barrio. Una de las ventanas de la cocina, la que se orienta a la calle principal, funciona como mostrador del comercio. Raquel y Jaime son migrantes peruanos; llegaron a Córdoba en 2007 y tienen un bebé de un año de edad que nació en Córdoba. Al igual que Pedro y Estela, arribaron a esta ciudad con la ayuda de unos conocidos. El trabajo en un taller de costura y en viviendas compartidas fue su primera opción al llegar, situación que se modificó cuando "aparecieron" estos terrenos.

Las ciudades, como expusimos más arriba, resultan escenarios privilegiados para analizar las estrategias de supervivencia que despliegan las familias migrantes. La llegada misma al barrio -o mejor dicho al lugar que luego será sentido, vivido e identificado como "el barrio"- es una muestra de ello. Pero también lo es el modo en que los migrantes organizan y redefinen el espacio privado-doméstico, vinculado en especial a sus formas de inserción productiva. El modo en que se organiza y redefine dicho espacio en un marco territorial específico, en este caso en el barrio Los Artesanos de la ciudad de 
Córdoba, se articula con los recorridos laborales más comunes entre las y los migrantes peruanos en función de la segmentación del mundo del trabajo a partir del género, el origen étnico-nacional y la pertenencia de clase. A su vez, esto se relaciona con una idea presente en muchas familias migrantes: que el autoempleo, en relación con el trabajo por cuenta propia, puede llegar a evitar situaciones de explotación laboral y también posibilitar una estabilidad socioeconómica que redundará en una mayor estabilidad del proyecto migratorio.

Las trayectorias laborales de los y las migrantes de origen peruano manifiestan una importante uniformidad. El empleo doméstico -que concentra a un alto porcentaje de mujeres-, la construcción -que orienta el trabajo de muchos varones-, y la costura -que involucra tanto mano de obra femenina como masculina-, son sus ocupaciones principales. ${ }^{21}$ Asimismo, un amplio número de familias posee en sus casas pequeños comercios informales de venta de productos alimentarios, muchos de ellos de comida peruana, lo cual constituye una ayuda más al ingreso familiar. La demanda de mujeres y varones migrantes para incorporarse en nichos laborales concretos permite visualizar los procesos de etnización -y también de generización- de determinados sectores del mercado de trabajo, en especial de los que se caracterizan por su precariedad, su desvalorización y su alta informalidad, lo cual es un factor clave en la constitución de las desigualdades sociales.

La etnización de la fuerza de trabajo en ámbitos urbanos, expresada en términos de adscripción nacional, opera como un recurso para conseguir trabajo, aprender y especializarse en alguna de las actividades que reúnen a los y las migrantes (Trpin y Vargas, 2005).22 Para una gran mayoría las tareas que desempeñan en Córdoba no son una extensión de aquellas que realizaban en Perú en el contexto premigratorio. Sin embargo, son las que organizan y orientan la migración e inciden fuertemente en la cotidianeidad posmigratoria. ${ }^{23}$ Antes de

${ }^{21}$ Y no sólo en el barrio, sino en la ciudad y en el resto del país. De modo principal, esos son los principales nichos laborales de los y las migrantes peruanas en Argentina.

${ }^{22} \mathrm{Si}$ bien no es posible afirmar que existe una relación lineal entre una determinada adscripción étnica-nacional y un tipo de oficio (Trpin y Vargas, 2005), es marcada la segmentación del mercado laboral a partir del origen étnico-nacional. Los migrantes de los países vecinos en Córdoba, en especial bolivianos, paraguayos y peruanos, se incorporan mayoritariamente en ciertos puestos de trabajo y no en otros, lo que da cuenta de esa relación.

${ }^{23}$ Grieco y Boyd (1998) plantean tres secuencias del proyecto migratorio: la etapa premigratoria, el acto de migrar y la etapa posmigratoria, vinculada a las estrategias que despliegan las y los migrantes en pos de la consolidación de ese proyecto. 
emprender la migración los migrantes, varones y mujeres, poseen información precisa acerca de dichos espacios de inserción laboral. Como bien lo plantea Estela, tanto ella como Pedro, sabiendo que la costura es la actividad central que desarrollan los migrantes peruanos en Córdoba y en Argentina en general, se "prepararon" especialmente en ese oficio antes de dejar Lima. Según nos relató Estela en una de nuestras charlas, fue una mujer quien los "trajo". Esta mujer, también peruana y a la que Estela considera "su otra madre" (Estela, 17 de octubre de 2012, Córdoba), tenía al momento de su llegada, y aún lo tiene, su propio taller de costura en el barrio Alberdi de la ciudad de Córdoba, en el cual trabajan y viven otros migrantes peruanos, tanto varones como mujeres.

En términos generales, las mujeres peruanas se concentran en actividades definidas como "femeninas", es decir, aquellas que son concebidas como una extensión de las tareas domésticas (Jelin, 2010: 65), como es el servicio doméstico y la costura. Para los varones, si bien la construcción es una inserción "masculina” extendida para los migrantes de los países limítrofes en Argentina (bolivianos, paraguayos y peruanos especialmente), la costura disputa esa categorización en tanto son ellos quienes, a partir de la etnización del mercado de trabajo, se incorporan en trabajos considerados "femeninos".

Entre las familias que habitan en Los Artesanos, el empleo doméstico y la construcción se desarrollan fuera del barrio, mientras que el trabajo de costura está fuertemente ligado a la espacialidad barrial. A pesar de que algunos de los migrantes, varones y mujeres, trabajan en talleres de costura que están ubicados fuera del barrio, la mayoría posee el taller en su propia casa. Casi todas las tardes que estuvimos en el barrio vimos que ingresaban camionetas "de afuera" de donde se cargaban y descargaban grandes bolsas negras con ropa. Esta dinámica se replica en varias casas del barrio y da cuenta de la importancia de la costura como estrategia de subsistencia para un amplio conjunto de familias peruanas.

El hecho de que el taller de costura se encuentre ubicado en la casa, especialmente en el espacio destinado a la cocina, plantea redefiniciones de las fronteras entre lo público y lo privado-doméstico. Tradicionalmente el espacio urbano ha ido construyendo dos esferas sociales diferenciadas: el mundo de la producción y el trabajo, y el mundo de la reproducción asociado a la casa y a la familia. Conforme a este escenario, el patrón clásico de división del trabajo establecía que los hombres salían a trabajar fuera de la barriada para asegurar el ingreso monetario, mientras que las mujeres se quedaban en el barrio a 
cargo tanto de las tareas domésticas como de las gestiones sobre los servicios básicos para el barrio (Jelin, 2010: 55).

En los retratos etnográficos del barrio, las mujeres peruanas emergen como las gestoras principales y activas de la supervivencia familiar y barrial. Durante el día, y principalmente entre semana, en el barrio se observan especialmente mujeres y niños. A los varones, por su parte, se les suele ver por las tardes, cuando retornan de las jornadas laborales que comienzan al amanecer, y sobre todo los fines de semana. Se les ve caminando por las calles, descansando o trabajando en mejorar sus propias casas. Pero también hay un grupo de migrantes peruanos varones para quienes el barrio y su propia casa son su lugar de trabajo. Para muchas familias el espacio privado-doméstico resulta ser también el lugar del trabajo productivo, en particular para quienes se dedican a la costura, sean varones o mujeres.

La modalidad de trabajo de costura es percibida por quienes lo realizan como inestable, pues depende de una demanda que fluctúa constantemente. La dinámica de esta actividad en el barrio se funda en los encargos que las fábricas de indumentarias u otros talleres textiles hacen a los propios migrantes. De modo fundamental, existen dos formas de cumplimentar dichos encargos: en primer lugar, los propios migrantes deben llegar hasta distintos puntos de la ciudad, siempre en colectivo, a buscar el trabajo, traerlo a su casa y, una vez terminado, llevarlo ellos mismos; en segundo lugar, los responsables de las fábricas y de los talleres textiles se ocupan de traer el material al barrio y luego, una vez que el trabajo está finalizado, lo vienen a retirar, generalmente en camionetas.

El trabajo de costura en la casa tiene sus ventajas y sus desventajas para quienes viven en Los Artesanos. Si bien "es cómodo", responde a las expectativas del autoempleo y garantiza la presencia en la vivienda para evitar que ésta sea "ocupada”, el hecho de tener las máquinas de coser en la casa puede generar también inseguridad entre los miembros de la familia:

Ahora nos compramos tres máquinas para trabajar, pero que lo malo de eso es que ya no puedes salir tanto porque cuando te ven que tienes ya están más atentos a cuando uno se va de su casa [Estela, 26 de septiembre de 2012, Córdoba].

La cuestión de la inseguridad es estructurante de las prácticas y formas de organización barrial. La "presencia" en las viviendas así como 
la solidaridad entre los vecinos, se vuelve un factor relevante de la cotidianeidad en Los Artesanos. Esta solidaridad se refuerza frente a los de "fuera", que pueden llegar a poner en peligro la estabilidad alcanzada, y también frente a los propios habitantes, en especial frente a aquellos que no forman parte de los circuitos de solidaridad y ayuda mutua que se fueron gestando y consolidando en el barrio.

La movilidad hacia el trabajo por cuenta propia puede concebirse también como la búsqueda de medios alternativos de subsistencia, siempre en un abanico acotado de opciones. Para los y las migrantes peruanos esta forma de trabajo se reduce a unas pocas actividades, en especial la costura y el comercio informal. En las actividades textiles participa toda la familia y es uno de los nichos laborales más buscados por las y los migrantes peruanos. A diferencia de los pequeños comercios informales situados en las viviendas que funcionan como "ayuda" al ingreso familiar, el trabajo de costura resulta el principal sustento de la familia en su conjunto.

En general, los pequeños comercios son atendidos por mujeres, muchas de las cuales tienen además un trabajo fuera del barrio, fundamentalmente como empleadas domésticas en casas de familias. Éste es el caso de Adriana; tanto ella como Roberto, su marido, trabajan fuera del barrio, ella como empleada doméstica y él en la construcción. Cuando Adriana retorna de su trabajo, cerca de las tres de la tarde, y después de atravesar gran parte de la ciudad, se ocupa del pequeño comercio de productos alimentarios (gaseosas, leche, yogurt, etc.) que tiene en su casa. Al igual que en el resto de las viviendas donde se ubican estos comercios, la ventana de la cocina-comedor funciona como mostrador. Es importante destacar que estos pequeños comercios informales no cuentan con una variedad importante de productos, no los surten proveedores sino que las mismas personas que los manejan van a comprarlos al "centro" de la ciudad para luego revenderlos en el barrio.

$\mathrm{Al}$ contrario de los pequeños comercios que se orientan hacia las necesidades de los vecinos del barrio (que son las únicas personas que circulan por Los Artesanos), el trabajo de costura está dirigido a fábricas y negocios ubicados fuera del mismo, aunque también se pueden incluir la confección y los arreglos de prendas de los propios vecinos. Las condiciones de trabajo de quienes se dedican a esta actividad son precarias, dentro del universo mismo de la precariedad del barrio. El espacio reservado al taller, el cual resulta ser en todos los casos que hemos podido observar el mismo reservado a la cocina y al comedor, 
no reúne las condiciones de ventilación e infraestructura para desarrollar dicho trabajo. Ahora bien, pese a la precariedad y a la informalidad de la labor de costura, el hecho de trabajar por cuenta propia les permite a las y los migrantes escapar de ciertas lógicas de explotación que caracterizan a las actividades textiles que ocupan a mujeres y varones migrantes de origen sudamericano en Argentina. ${ }^{24}$

Al llegar a este punto nos preguntamos por las implicaciones del hecho de que el varón desempeñe un trabajo definido socialmente como "femenino" en términos de roles de género y, al mismo tiempo, por los sentidos que adquiere en el marco de las relaciones familiares la reconfiguración del ámbito de la reproducción como espacio productivo. En los estudios de género hay una abundante producción científica que gira en torno a las significaciones de la intervención extendida de la mujer en la esfera productiva, en especial desde la década de los setenta del siglo Xx. Muchos de estos estudios concluyen que la creciente incorporación femenina en el ámbito de la producción no ha simbolizado para las mujeres un abandono ni tampoco una renegociación de los roles de género en la esfera de la reproducción. En este contexto, el incremento de las "presencias" femeninas ha sido uno de los principales efectos de la progresiva participación de la mujer en el ámbito productivo, con referencia fundamentalmente a las mujeres de los sectores populares, en tanto su intervención en dicho ámbito se ha sumado a sus tareas en el espacio reproductivo, el cual se continúa considerando y viviendo como estrictamente femenino (Ariza, 2000; Magliano, 2007, 2009, 2013; Parella, 2003; Suárez Navas, 2004).${ }^{25}$ Dentro de este escenario, la incorporación laboral de un amplio conjunto de mujeres ha intensificado las desigualdades de género y ha escondido los sentidos de la división sexual del trabajo que, a la vez que ha preservado la esfera doméstica como competencia exclusiva femenina,

${ }^{24}$ En Argentina en general y en Córdoba en particular, la costura es fundamentalmente un trabajo "de migrantes", a diferencia, por ejemplo, del trabajo en la construcción e incluso del servicio doméstico en que participan varones y mujeres migrantes, respectivamente, y también mujeres y varones argentinos de los sectores populares. Con relación a este nicho laboral en varios centros urbanos del país, Córdoba no es la excepción: han proliferado los denominados "talleres clandestinos" en donde viven y trabajan en condiciones de explotación mujeres, varones y niños, muchos de ellos migrantes de los países vecinos, Bolivia y Perú especialmente.

${ }^{25}$ En una investigación previa profundizamos sobre las implicaciones de las "presencias" de las mujeres migrantes, más precisamente de las mujeres bolivianas en Argentina, en términos de reproducción de desigualdades sociales. Para más información sobre esta cuestión véase Magliano, 2013. 
ha condicionado el desarrollo de trayectorias laborales específicas dentro de un mercado de trabajo segmentado en función del género, la etnicidad y la clase social (Magliano, 2009: 339).

Sin embargo, son escasas las investigaciones que han avanzado en otra realidad subterránea que atraviesa a muchas familias de sectores populares, en este caso a familias migrantes en la ciudad de Córdoba, esto es el hecho de que el varón, a partir de la realización de tareas concebidas socialmente como "femeninas", reconfigure el espacio privado-doméstico como espacio productivo. En nuestro trabajo de campo, pudimos observar que las tareas de costura, llevadas a cabo tanto por los varones como por las mujeres, no buscan esconderse ni justificarse; al contrario, los varones las viven con cierto "orgullo" en tanto manifiestan que son requeridos para desempeñar una función que "pocos" (en referencia a los argentinos) quieren hacer, legitimando de este modo su "presencia" en el lugar de destino. Además, el hecho de que el varón trabaje en su casa, más precisamente en la cocina, desarrollando una tarea constituida como femenina -conjuntamente con su esposa e incluso hijas e hijos- no implica necesariamente una renegociación de los roles de género en el ámbito familiar. Las actividades vinculadas a la esfera doméstica (referidas a las tareas de cuidado de los niños, gestión y organización del hogar) dependen exclusivamente de las mujeres. Por otra parte, son los varones quienes toman las decisiones vinculadas con el ámbito de la producción y a la vez son quienes se encargan principalmente del mantenimiento y mejora de la vivienda.

Las especificidades de ciertas trayectorias laborales para los y las migrantes, como el trabajo de costura, responden más a dinámicas de subsistencia que a un cuestionamiento de roles y estereotipos de género. Asimismo revelan que los migrantes, varones y mujeres, son actores sociales activos que comprenden su entorno y despliegan diversas estrategias en el marco del proyecto migratorio. Los modos de incorporación laboral que suponen la reorganización del espacio privadodoméstico como espacio productivo de la familia en su conjunto son una muestra de esas estrategias de supervivencia en escenarios de exclusión y marginalidad urbanas. 
Magliano, Perissinotti y Zenklusen, ESTRATEGIAS EN TORNO A LAS FORMAS

\section{Palabras finales}

Las formas de apropiación y organización del espacio del barrio Los Artesanos ponen de manifiesto las estrategias que ponen en juego las familias migrantes, en este caso peruanas, en pos de asegurar su subsistencia y hacer frente a las diversas formas de desigualdades sociales presentes en los ámbitos urbanos, en este caso en la ciudad de Córdoba en Argentina. A lo largo de este trabajo analizamos los procesos que vinculan las formas de apropiación y organización del espacio urbano con las dinámicas migratorias recientes en Córdoba. Para las familias migrantes que llegaron a Córdoba en los últimos años, la cuestión de la vivienda ha adquirido significaciones especiales en el marco del proyecto migratorio. La imposibilidad de acceder a la propiedad por los canales formales -e incluso de alquilar viviendas por esos canalesen un escenario de exclusiones y desigualdades sociales, es reconfigurado por los y las migrantes como "posibilidad" a la hora de activar otras estrategias para poder acceder a una casa propia, como resulta ser la "toma" de terrenos fiscales que se encuentran deshabitados. Justamente a través de estos recorridos se fueron constituyendo varios de los barrios urbano-marginales en la periferia cordobesa en las últimas décadas. En este sentido, en este trabajo hemos enfatizado la importancia de recuperar la dimensión espacial para reflexionar sobre los procesos de producción y reproducción de las desigualdades sociales en las sociedades contemporáneas.

Asimismo, pusimos de relieve cómo las trayectorias laborales, condicionadas por la segmentación del mundo del trabajo a partir de la condición de género, el origen étnico-nacional y la pertenencia de clase, se articulan a modos específicos de negociación del espacio territorial y también del propio espacio privado-doméstico. Los nichos laborales de inserción típicos de las y los migrantes peruanos en Córdoba -y no sólo de ellos- rompen y disputan modelos tradicionales de construcción de los universos públicos y privados-domésticos y también ciertas definiciones sobre los trabajos femeninos y masculinos. Estas rupturas y disputas no implican necesariamente cambios en los roles y relaciones de género, sino que se asientan en las mismas estrategias migratorias que despliegan las y los migrantes peruanos, algunas de ellas incluso en el contexto premigratorio (como en el caso de Pedro y Estela que "aprendieron" costura antes de emprender la migración), los cuales resultan centrales en el sostenimiento y consolidación de la migración. 


\section{Bibliografía}

Ariza, Marina (2000), Ya no soy la que dejé atrás... Mujeres migrantes en República Dominicana, México, Instituto de Investigaciones Sociales / Plaza y Valdés. Arriagada, Irma (2006), "Desigualdades, exclusiones y discriminaciones de género en el mercado laboral en América Latina”, en Gioconda Herrera (coord.), La persistencia de la desigualdad. Género, trabajo y pobreza en América Latina, Quito, Conamu / Flacso Ecuador, pp. 21-48.

Auyero, Javier (1999), “This is Like the Bronx, Isn't It? Lived Experiences of Marginality in an Argentine Slum”, International Journal of Urban and Regional Research, núm. 23, pp. 45-69.

Barrancos, Dora (2008), Mujeres entre la casa y la plaza, Buenos Aires, Sudamericana.

Bolos, Silvia (2008), Mujeres y espacio público: construcción y ejercicio de la ciudadanía, México, Universidad Iberoamericana.

Carrasco, Cristina (2003), "La sostenibilidad de la vida humana: ¿un asunto de mujeres?”, en Magdalena León (comp.), Mujeres y trabajo: cambios impostergables, Porto Alegre, Veraz Comunicação, pp. 11-49.

Carrasco, Cristina y Maribel Mayordomo (1999), "Tiempos, trabajos y organización sociales: reflexiones en torno al mercado laboral femenino”, en Cristina Carrasco (coord.), Mujeres y economía. Nuevas perspectivas para viejos y nuevos problemas, Barcelona, Icaria / Antrazyt, pp. 125-172.

Carrasquer, Pilar, Teresa Torns, Elisabet Tejero y Alfonso Romero (1998), "El trabajo reproductivo", Papers, núm. 55, pp. 95-114.

Censo Provincial de Población (2008), Dirección de Estadísticas Sociodemográficas, Córdoba.

Cerrutti, Marcela (2003), "Trabajo, organización familiar y relaciones de género en Buenos Aires", en Catalina Wainerman (comp.), Familia, trabajo y género. Un mundo de nuevas relaciones, Buenos Aires, Fondo de Cultura Económica, pp. 105-152.

Cerrutti, Marcela (2005), "La migración peruana a la Ciudad de Buenos Aires: su evolución y características”, Población de Buenos Aires, vol. 2, núm. 2, pp. 7-28.

Falcón Aybar, María del Carmen y Eduardo Bologna (2013), "Migrantes antiguos y recientes: una perspectiva comparada de la migración peruana a Córdoba, Argentina”, Migraciones Internacionales, vol. 7, núm. 1, pp. 235-266.

García, Brígida y Orlandina de Oliveira (2007), "Trabajo extradoméstico y relaciones de género: una nueva mirada”, en María Alicia Gutiérrez (comp.), Género, familias y trabajo: rupturas y continuidades. Desafíos para la investigación política, Buenos Aires, Clacso, pp. 49-87.

Grasmuck, Sherri y Patricia Pessar (1999), Between Two Islands: Dominican International Migration, Berkeley, University of California Press.

Gregorio, Carmen (1998), Migración femenina. Su impacto en las relaciones de género, Madrid, Narcea. 
Grieco, Elizabeth y Mónica Boyd (1998), "Women and Migration: Incorporating Gender into International Migration Theory", Working Papers, Florida, Center for the Study of Population.

De la O, María Eugenia y Rocío Guadarrama (2006), "Cultura, identidades laborales y de género en América Latina”, en Ximena Díaz, Lorena Godoy y Antonio Stecher (comps.), Trabajo, identidad y vínculo social. Reflexiones y experiencias en el capitalismo flexible, Santiago de Chile, Centro de Estudios de la Mujer, Universidad Diego Portales, pp. 158-184.

Guber, Rosana (2004), La etnografía. Método, campo y reflexividad, Buenos Aires, Norma.

Jelin, Elizabeth (2010), Pan y afectos. La transformación de las familias, Buenos Aires, Fondo de Cultura Económica.

Lagarde, Marcela (2003), Los cautiverios de las mujeres: madres, esposas, monjas, putas, presas y locas, México, UNAM.

León Prado, Rossana (2010), "Construcción de la nacionalidad, políticas de Estado y peruanos en la ciudad de Córdoba”, tesis de maestría en Antropología, Facultad de Filosofía y Humanidades, Universidad Nacional de Córdoba.

Lomnitz, Larissa (1994), Redes sociales, cultura y poder: ensayos de antropología latinoamericana, México, Flacso / Porrúa.

Magliano, María José (2007), "Migración de mujeres bolivianas hacia Argentina: cambios y continuidades en las relaciones de género", Les Cahiers Alhim, Amérique Latine histoire et mémoire, núm. 14, pp. 41-62.

Magliano, María José (2009), "El rol de la mujer boliviana en el proceso migratorio hacia Córdoba (1947-2001)", tesis de doctorado en Historia, Córdoba, Facultad de Filosofía y Humanidades, Universidad Nacional de Córdoba.

Magliano, María José (2013), "Los significados de vivir 'múltiples presencias': mujeres bolivianas en Argentina”, Migraciones Internacionales, vol. 7, núm. 24, pp. 165-195.

Maquiera, Virginia (2001), "Género, diferencia y desigualdad", en Elena Beltrán y Virginia Maquiera (coords.), Feminismos. Debates teóricos contemporáneos, Madrid, Alianza, pp. 127-190.

Marcuse, Peter (1993), "What's so New about Divide Cities", Urban Regional Research, vol. 17, núm. 3, pp. 355-365.

Merklen, Denis (1991), Asentamientos en La Matanza. La terquedad de lo nuestro, Buenos Aires, Catálogos.

Murillo, Soledad (2006), El mito de la vida privada. De la entrega al tiempo propio, Madrid, Siglo XXI.

Parella, Sonia (2003), Mujer inmigrante y trabajadora: la triple discriminación, Barcelona, Anthropos.

Pedone, Claudia (2006), Estrategias migratorias y poder. "Tú que jalas a los tuyos", Quito, Abya Yala.

Rosas, Carolina (2007), “‘Migras tú, migro yo o migramos juntos?’. Los condi- 
cionantes de género en las decisiones migratorias de parejas peruanas destinadas en Buenos Aires", Memorias de las IX Jornadas Argentinas de Estudios de la Población, Huerta Grande, Córdoba, 31 de octubre a 2 de noviembre.

Rosas, Carolina (2008), "Mujeres migrantes, mujeres proveedoras: transformaciones y conflictos en las feminidades y las masculinidades", Actas de las IX Jornadas de Historia de las Mujeres y IV Congreso Iberoamericano de Estudios de Género, Rosario, Santa Fe, 30 de julio a 1 de agosto.

Rosas, Carolina (2010), Implicaciones mutuas entre el género y la migración. Mujeres y varones peruanos arribados a Buenos Aires entre 1990 y 2003, Buenos Aires, Eudeba.

Sassen, Saskia (2007), Una sociología de la globalización, Buenos Aires, Katz.

Segato, Rita (2006), "En busca de un léxico para teorizar la experiencia territorial contemporánea”, Politika. Revista de Ciencias Sociales, núm. 2, pp. 129-148.

Suárez Navas, Liliana (2004), "Transformaciones de género en el campo transnacional. El caso de mujeres migrantes en España”, Revista de Estudios de Género. La Ventana, núm. 26, pp. 293-331.

Terrones Ribas, Albert (2005), "Política social y exclusión residencial de las mujeres inmigrantes en Madrid y Barcelona”, en Carlota Solé y Luis Flaquer (coords.), El uso de las políticas sociales por las mujeres inmigrantes, Madrid, Instituto de la Mujer, pp. 193-298.

Torns, Teresa (2008), "El trabajo y el cuidado: cuestiones teórico-metodológicas desde la perspectiva de género", Empiria. Revista de Metodología de Ciencias Sociales, núm. 15, pp. 53-73.

Trpin, Verónica y Patricia Vargas (2005), “Trabajadores migrantes: entre la clase y la etnicidad. Potencialidad de sus usos en la investigación socioantropológica”, ponencia presentada en VII Congreso Nacional de Estudios del Trabajo, Asociación Argentina de Especialistas en Estudios del Trabajo, Buenos Aires.

Vaggione, Juan Marco y Gerardo Avalle (2007), "El barrio y sus mujeres: la cotidianeidad en los movimientos piqueteros de Córdoba", Anuario, núm. 10 , pp. $807-822$.

Wacquant, Loïc (2007a), Los condenados de la ciudad. Gueto, periferias y Estado, Buenos Aires, Siglo XXI.

Wacquant, Loïc (2007b), Parias urbanos. Marginalidad en la ciudad a comienzo del milenio, Buenos Aires, Manantial.

Zamorano Villarreal, Claudia (2003), "La aplicación de la noción de estrategia en los estudios urbanos franceses: las estrategias residenciales”, Sociológica, vol. 18, núm. 51, pp. 165-187. 
Magliano, Perissinotti y Zenklusen, ESTRATEGIAS EN TORNO A LAS FORMAS

\section{Acerca de las autoras}

María José Magliano es doctora en Historia por la Universidad Nacional de Córdoba (UNC), Argentina, y licenciada en Historia por la misma universidad. Es investigadora asistente del Consejo Nacional de Investigaciones Científicas y Técnicas (Conicet) con lugar de trabajo en el Centro de Investigaciones y Estudios sobre Cultura y Sociedad (CIECS-Conicet / UNC). Es profesora de la Escuela de Historia de la Facultad de Filosofía y Humanidades de la UNC. En la actualidad codirige el programa de investigación "Multiculturalismo, migraciones y desigualdad en América Latina” (CEA-UNC y CIECS-Conicet / UNC). Sus principales temas de interés son: migraciones y género; relación entre migración, género y políticas en la región sudamericana; migración, interseccionalidad y desigualdades sociales.

María Victoria Perissinotti es maestranda en Antropología por la Universidad Nacional de Córdoba (UNC), Argentina, y licenciada en Comunicación Social por la misma universidad. Es integrante del programa de investigación "Multiculturalismo, migraciones y desigualdad en América Latina” (CEA-UNC y CIECS-Conicet / UNC). Sus principales temas de interés son: mujeres migrantes y acción colectiva; prácticas políticas y migración; espacios y migraciones.

Denise Zenklusen es becaria doctoral del Consejo Nacional de Investigaciones Científicas y Técnicas (Conicet) con lugar de trabajo en el Centro de Investigaciones y Estudios sobre Cultura y Sociedad (CIECSConicet / UNC), en Córdoba, Argentina. Es maestranda en Antropología Social por la Universidad Nacional de Córdoba (UNC) y licenciada en Comunicación Social por la misma universidad. Es integrante del programa de investigación "Multiculturalismo, migraciones y desigualdad en América Latina” (CEA-UNC y CIECS-Conicet / UNC). Sus principales temas de interés son: migraciones latinoamericanas; relaciones de género y generacionales en familias migrantes; jóvenes migrantes. 
